\title{
Chronic venous insufficiency, cardiovascular disease, and mortality: a population study
}

Citation for published version (APA):

Prochaska, J. H., Arnold, N., Falcke, A., Kopp, S., Schulz, A., Buch, G., Moll, S., Panova-Noeva, M., Junger, C., Eggebrecht, L., Pfeiffer, N., Beutel, M., Binder, H., Grabbe, S., Lackner, K. J., Ten Cate-Hoek, A., Espinola-Klein, C., Munzel, T., \& Wild, P. S. (2021). Chronic venous insufficiency, cardiovascular disease, and mortality: a population study. European Heart Journal, 42(40), 4157-4165.

https://doi.org/10.1093/eurheartj/ehab495

Document status and date:

Published: 21/10/2021

DOI:

10.1093/eurheartj/ehab495

Document Version:

Publisher's PDF, also known as Version of record

Document license:

Taverne

Please check the document version of this publication:

- A submitted manuscript is the version of the article upon submission and before peer-review. There can be important differences between the submitted version and the official published version of record.

People interested in the research are advised to contact the author for the final version of the publication, or visit the DOI to the publisher's website.

- The final author version and the galley proof are versions of the publication after peer review.

- The final published version features the final layout of the paper including the volume, issue and page numbers.

Link to publication

\footnotetext{
General rights rights.

- You may freely distribute the URL identifying the publication in the public portal. please follow below link for the End User Agreement:

www.umlib.nl/taverne-license

Take down policy

If you believe that this document breaches copyright please contact us at:

repository@maastrichtuniversity.nl

providing details and we will investigate your claim.
}

Copyright and moral rights for the publications made accessible in the public portal are retained by the authors and/or other copyright owners and it is a condition of accessing publications that users recognise and abide by the legal requirements associated with these

- Users may download and print one copy of any publication from the public portal for the purpose of private study or research.

- You may not further distribute the material or use it for any profit-making activity or commercial gain

If the publication is distributed under the terms of Article $25 \mathrm{fa}$ of the Dutch Copyright Act, indicated by the "Taverne" license above, 


\title{
Chronic venous insufficiency, cardiovascular disease, and mortality: a population study
}

\begin{abstract}
Jürgen H. Prochaska ${ }^{1,2,3}$, Natalie Arnold ${ }^{1}$, Andrea Falcke', Sabrina Kopp (1) ${ }^{1}$, Andreas Schulz ${ }^{1}$, Gregor Buch ${ }^{1,4}$, Sophie Moll (1) ${ }^{1}$, Marina Panova-Noeva ${ }^{2,3}$, Claus Jünger ${ }^{1}$, Lisa Eggebrecht ${ }^{1}$, Norbert Pfeiffer ${ }^{5}$, Manfred Beutel ${ }^{(1)}{ }^{6}$, Harald Binder $\mathbb{( D}^{4,7}$, Stephan Grabbe $\mathbb{( 1}^{8}{ }^{8}$, Karl J. Lackner ${ }^{9,3}$, Arina ten Cate-Hoek ${ }^{10}$, Christine Espinola-Klein ${ }^{11}$, Thomas Münzel (1) ${ }^{11,3,2}$, and Philipp S. Wild (1) ${ }^{1,2,3 *}$
\end{abstract}

\begin{abstract}
${ }^{1}$ Preventive Cardiology and Preventive Medicine, Department of Cardiology, University Medical Center of the Johannes Gutenberg University Mainz, Langenbeckstr. 1, Mainz 55131, Germany; ${ }^{2}$ Center for Thrombosis and Hemostasis, University Medical Center of the Johannes Gutenberg University Mainz, Langenbeckstr. 1, Mainz 55131, Germany; ${ }^{3}$ German Center for Cardiovascular Research (DZHK), partner site Rhine Main, Mainz 55131, Germany; ${ }^{4}$ Institute of Medical Biostatistics, Epidemiology and Informatics, University Medical Center of the Johannes Gutenberg University Mainz, Langenbeckstr. 1, Mainz 55131, Germany; ${ }^{5}$ Department of Ophthalmology, University Medical Center of the Johannes Gutenberg University Mainz, Langenbeckstr. 1, Mainz 55131, Germany; ${ }^{6}$ Department of Psychosomatic Medicine and Psychotherapy, University Medical Center of the Johannes Gutenberg University Mainz, Langenbeckstr. 1, Mainz 55131, Germany; ${ }^{7}$ Institute of Medical Biometry and Statistics, Faculty of Medicine and Medical Center, University of Freiburg, Freiburg 79104, Germany; ${ }^{8}$ Department of Dermatology, University Medical Center of the Johannes Gutenberg University Mainz, Langenbeckstr. 1, Mainz 55131, Germany; ${ }^{9}$ Institute of Clinical Chemistry and Laboratory Medicine, University Medical Center of the Johannes Gutenberg University Mainz, Langenbeckstr. 1, Mainz 55131, Germany; ${ }^{10}$ Department of Vascular Medicine, Heart and Vascular Center, University Medical Center Maastricht, Maastricht 6200 MD, the Netherlands; and ${ }^{11}$ Department of Cardiology—Cardiology I, University Medical Center of the Johannes Gutenberg University Mainz, Langenbeckstr. 1, Mainz 55131, Germany
\end{abstract}

Received 17 February 2021; revised 3 June 2021; editorial decision 5 July 2021; accepted 9 August 2021; online publish-ahead-of-print 13 August 2021

See page $\mathbf{4 1 6 6}$ for the editorial comment for this article 'The legs are a pathway to the heart: connections between chronic venous insufficiency and cardiovascular disease', by N.M. Hamburg, https://doi.org/10.1093/eurheartj/ehab589.

Aims Evidence regarding the health burden of chronic venous insufficiency (CVI), its clinical determinants, and impact on outcome is scarce.

Methods and results

Systematic phenotyping of CVI according to established CEAP (Clinical-Etiologic-Anatomic-Pathophysiologic) classi2012 to April 2017. Prevalence was calculated age- and sex-specifically. Multivariable Poisson regression models were calculated to evaluate the relation of CVI with cardiovascular comorbidities. Survival analyses were carried out to assess the CVI-associated risk of death. Replication of findings was done in an independent cohort study (MyoVasc, NCT04064450). The prevalence of telangiectasia/reticular, varicose veins, and CVI was 36.5\% [95\% confidence interval (Cl), 35.6-37.4\%], 13.3\% [12.6-13.9\%], and 40.8\% [39.9-41.7\%], respectively. Age, female sex, arterial hypertension, obesity, smoking, and clinically overt cardiovascular disease were identified as clinical determinants of CVI. Higher CEAP classes were associated with a higher predicted 10-year risk for incident cardiovascular disease in individuals free of cardiovascular disease $(n=9923)$. During a mean follow-up of $6.4 \pm 1.6$ years, $C V I$ was a strong predictor of all-cause death independent of the concomitant clinical profile and medication [hazard ratio (HR) $1.46(95 \% \mathrm{Cl} 1.19-1.79), P=0.0003]$. The association of $\mathrm{CVI}$ with an increased risk of all-cause death was externally validated in the MyoVasc cohort [HR 1.51 (95\% Cl 1.11-2.05), $P=0.009]$.

Conclusion Chronic venous insufficiency is highly prevalent in the population and is associated with the presence of cardiovascular risk factors and disease. Individuals with CVI experience an elevated risk of death, which is independent of age and sex, and present cardiovascular risk factors and comorbidities.

* Corresponding author. Tel: +49 06131 17-8460, Fax: +49 06131 17-8640, Email: philipp.wild@unimedizin-mainz.de

Published on behalf of the European Society of Cardiology. All rights reserved. (c) The Author(s) 2021. For permissions, please email: journals.permissions@oup.com. 


\section{Graphical Abstract}

\section{Chronic Venous Insufficiency}

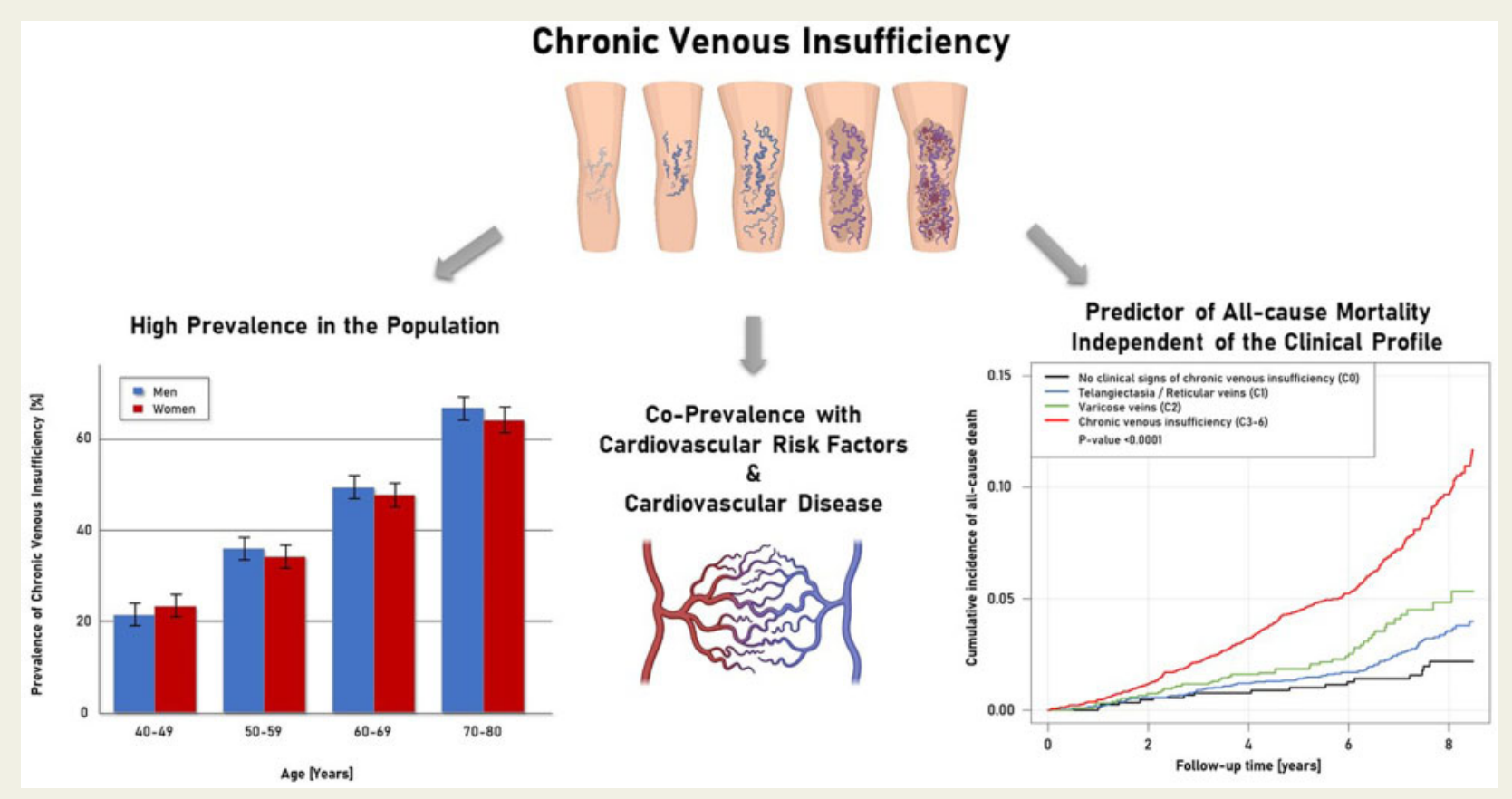

Chronic venous insufficiency is highly prevalent in the general population and associated with arterial cardiovascular disease and an increased risk of allcause mortality.

\section{Introduction}

Chronic venous insufficiency (CVI) refers to a spectrum of entities, which are related to both structural and functional pathologies of the venous system. ${ }^{1}$ The pathophysiology of CVI displays a complex interplay of venous valve dysfunction and venous hypertension with subsequent macro- and microcirculatory haemodynamic and vascular alterations. ${ }^{2}$ Telangiectasia, reticular venectasia, varicose veins, and CVI ranging from oedema to active skin ulcers represent the most common clinically visible manifestations of chronic venous disease. ${ }^{3}$

Venous insufficiency is highly prevalent in developed and industrialized countries, ${ }^{4}$ but estimates for the prevalence vary widely between study setting, geographic region, and methodology. ${ }^{5}$ Recent studies support the hypothesis that the pathophysiology of venous and arterial vascular disease share commonalities and are interrelated. ${ }^{6,7}$ However, there is a paucity of investigations exploring the interplay between venous and arterial cardiovascular disease ${ }^{8}$ and population-based studies exploring the relation of both vascular disease manifestations and the subsequent risk of death across the spectrum of venous insufficiency are currently not available.

The objectives of this study were (i) to provide current age- and sex-specific prevalence estimates for the clinical range of $\mathrm{CVI}$ in the population, (ii) to investigate the burden of cardiovascular risk factors and comorbidities in the spectrum of venous disease, and (iii) to evaluate the relevance of venous insufficiency for clinical outcome in the general population.

\section{Methods}

\section{Study design and population}

The Gutenberg Health Study (GHS) is a large population-based, prospective, single-centre cohort study conducted in Mid-Western Germany. In total, 12423 study participants aged 40-80 years were investigated in the GHS study centre between April 2012 and April 2017. No specific exclusion criteria beyond the ability to visit the study centre and understanding of the German language were set. Study protocol and documents were approved by the local ethics committee and data protection officer before study initiation. All study participants provided written informed consent and all study procedures have been performed in line with the principles outlined in the Declaration of Helsinki and the recommendations for Good Epidemiology Practice. Information on the study design of the GHS has been published recently. ${ }^{9}$

\section{Data assessment}

During the visit at the GHS study centre, participants underwent a standardized 5-h investigational plan according to standard operating procedures. Data quality control followed pre-defined plausibility criteria. Investigations included the assessment of cardiovascular risk factors and 
comorbidities via a computer-assisted personal interview, review of medical records, clinical examinations, and laboratory analysis of venous blood samples. Clinical examination included the pitting oedema test for the distinction of non-pitting and pitting oedema. ${ }^{10}$ The clinical condition of the lower limbs was recorded in a standardized fashion with digital photographs of the legs in standing position from pre-defined angles (front and back). Subsequent grading of the data was carried out via image reading by five independent investigators. Quality control of image reading was performed including the evaluation of inter- and intra-observer variabilities (Cohen's Kappa $=0.76$ and 0.80 , respectively). Information on symptoms related to venous disease (e.g. oedema, phlebitis, and leg pain) was assessed during a computer-assisted personal interview and in a standardized clinical examination. Information on all-cause mortality was obtained for all individuals via state registration offices.

\section{Categorization of venous insufficiency}

The presence of CVI was assessed according to the clinical presentation of the CEAP (Clinical-Etiologic-Anatomic-Pathophysiologic) classification scheme, which is most commonly used for standardized reporting in clinical and epidemiological studies. ${ }^{11}$ In brief, individuals were classified as follows: $\mathrm{CO}$-no visible signs of venous insufficiency, C1 - telangiectasia (C1a) or reticular veins (C1b), C2-varicose veins, C3-oedema, C4skin changes (C4a: pigmentation/eczema-C4b: lipodermatosclerosis/ white atrophy), $\mathrm{C} 5$ - healed venous ulcer, and C6 - active venous ulcer (Supplementary material online, Figure S1). On an individual level, each participant was classified to the highest $C$ class of both legs. Chronic venous insufficiency was defined by CEAP clinical stage $\geq 3$, whereas individuals of $\mathrm{CO}$ were categorized as being free of venous disease. The sample of individuals with CVI was stratified by the severity of disease according to C status into moderate (i.e. C3) and advanced CVI (i.e. C4-C6) and by the presence of venous symptoms.

\section{Validation cohort}

The MyoVasc Study (NCT04064450)—a large prospective cohort on heart failure based in Mainz, Germany-was used as an external validation cohort for investigating the relationship of CVI with all-cause mortality. Information on the rationale and design of the cohort including information on all study procedures has been reported in detail. ${ }^{12}$ In the MyoVasc cohort, assessment of CVI according to the clinical presentation of the CEAP classification scheme was carried out identically to the GHS cohort.

\section{Statistical analysis}

Discrete variables were described by relative and absolute frequencies, continuous variables by means with standard deviation or median value with 25th-75th percentiles (interquartile range, IQR), where appropriate. Prevalence for $\mathrm{C}$ classes and symptoms of CVI were calculated sexspecifically with $95 \%$ confidence intervals (Cls) and subsequently weighted for the age- and sex-specific distributions of the German population on 31 December 2014 and for the European Standard Population for translation of estimates to other populations. Cardiovascular disease was defined as a composite of atrial fibrillation, congestive heart failure, coronary and peripheral artery disease, stroke, or venous thrombo-embolism. In order to evaluate the relation between CEAP clinical categories and cardiovascular comorbidities, Poisson regression models with robust variance estimator and adjustment for potential confounders were used. This approach was chosen instead of less stable binomial regression models to overcome convergence problems. Prevalence ratios (PR) for categories of $\mathrm{CVI}$ as binary variable with individuals without signs of the disease as reference group were calculated. The risk for incident cardiovascular disease according to the clinical severity of CVI was evaluated using the Framingham 10-year risk score for cardiovascular disease. $^{13}$

Kaplan-Meier estimates were calculated to analyse survival according to the presence of CVI and the log-rank test was applied to compare survival distributions. Cox proportional hazards models were applied to evaluate whether CVI is an independent predictor of all-cause death. Due to the explorative nature of the study, a significance threshold was not defined and $P$-values were interpreted as continuous measure of statistical evidence. However, $95 \% \mathrm{Cl}$ are provided to guide interpretation of effects and relative differences in data. All statistical analyses were conducted in R, version 3.5.1 (R Foundation for Statistical Computing, Vienna, Austria).

\section{Results}

\section{Clinical characteristics of the population sample}

Information on the clinical status of CVI was available for 10664 individuals (Supplementary material online, Table S1). In the analysis sample, $48.8 \%$ of study participants were female and the mean age of the study sample was $59.5 \pm 10.8$ years. No signs of a venous insufficiency (C0) were detected in 906, whereas telangiectasia or reticular venectasies (C1) were identified in 3756, varicose veins (C2) in 1399, and clinically overt CVI (C3-C6) in 4603 individuals, of which 3361 presented with venous oedema (C3) and 1242 had skin changes (C4-C6). The clinical characteristics of the study sample according to the clinical conditions of the CEAP classification are displayed in Table 1. In brief, individuals with CVI were older and more likely to be female compared with individuals of CEAP class CO. The highest burden of traditional cardiovascular risk factors (i.e. arterial hypertension, diabetes mellitus, dyslipidaemia, family history of myocardial infarction and/or stroke, obesity, and smoking) was detected for individuals with $\mathrm{CVI}$, which was highest in individuals with skin changes (C4-C6) followed by individuals with venous oedema (C3). This finding was accompanied by a higher co-prevalence of cardiovascular disease. Except for chronic obstructive pulmonary disease, all cardiovascular comorbidities showed the highest prevalence in advanced CVI (C4-C6). In contrast, comparison of clinical characteristics between individuals with varicose veins and telangiectasia or reticular veins to individuals without venous insufficiency $(\mathrm{CO})$ indicated only minor distinctions.

\section{Prevalence of chronic venous insufficiency in the general population}

In the total sample, the prevalence of chronic venous diseases was $36.5 \%$ (95\% Cl 35.6-37.4\%) for telangiectasia and reticular venectasies (C1), 13.3\% (95\% Cl 12.6-13.9\%) for varicose veins (C2), and 40.8\% (95\% Cl 39.9-41.7\%) for CVI (C3-C6). Among all venous disease phenotypes, venous insufficiency with oedema (C3) showed the highest prevalence $(30.1 \%, 95 \% \mathrm{Cl} 29.2-31.0 \%)$, followed by venous insufficiency with non-acute skin changes $(C 4,10.5 \%, 95 \% \mathrm{Cl}$ 9.9-11.1\%) and venous insufficiency with ulceration (C5/C6, 0.2\%, 95\% Cl 0.1-0.3\%). Age- and sex-specific estimates for the burden of venous insufficiency in the general population are displayed in detail in Figure 1 and in Supplementary material online, Table S2. Sensitivity 
Table I Clinical characteristics of the study sample according to clinical signs of chronic venous insufficiency

\begin{tabular}{|c|c|c|c|c|c|}
\hline Characteristics & $\begin{array}{l}\text { No signs of } \\
\text { venous insufficiency } \\
(\mathrm{C} 0) \\
(n=906)\end{array}$ & $\begin{array}{l}\text { Telangiectasia/ } \\
\text { reticular veins } \\
(C 1) \\
(n=3756)\end{array}$ & $\begin{array}{l}\text { Varicose veins } \\
(C 2) \\
(n=1399)\end{array}$ & $\begin{array}{l}\text { Chronic venous } \\
\text { insufficiency } \\
\text { with oedema } \\
(C 3) \\
(n=3361)\end{array}$ & $\begin{array}{l}\text { Chronic venous } \\
\text { insufficiency with } \\
\text { skin changes } \\
(C 4-C 6) \\
(n=1242)\end{array}$ \\
\hline Age, years, median (IQR) & $51.0(45.0-58.0)$ & $56.0(49.0-65.0)$ & $59.0(51.0-68.0)$ & $65.0(56.0-72.0)$ & $67.0(59.0-74.0)$ \\
\hline Female sex, \% (n) & $23.4(212)$ & $54.4(2044)$ & $53.8(752)$ & $51.1(1718)$ & $37.4(464)$ \\
\hline \multicolumn{6}{|l|}{$\begin{array}{l}\text { Traditional cardiovascular } \\
\text { risk factors, \% (n) }\end{array}$} \\
\hline Arterial hypertension & $43.0(387)$ & $47.0(1761)$ & $44.9(627)$ & $67.0(2247)$ & $70.2(870)$ \\
\hline Diabetes mellitus & $7.2(65)$ & $6.8(256)$ & $6.9(96)$ & $15.8(528)$ & $19.5(241)$ \\
\hline Dyslipidaemia & $45.3(410)$ & 40.5 (1517) & $37.7(526)$ & $51.0(1711)$ & $55.2(685)$ \\
\hline $\begin{array}{l}\text { Family history of myocardial } \\
\text { infarction or stroke }\end{array}$ & $21.9(198)$ & $24.0(902)$ & $21.1(295)$ & $25.5(858)$ & $23.8(295)$ \\
\hline Obesity & $17.5(159)$ & $17.8(668)$ & $14.9(208)$ & $41.3(1388)$ & $40.5(503)$ \\
\hline Smoking (current) & $19.1(173)$ & $16.4(614)$ & $13.9(194)$ & $12.8(431)$ & $16.0(198)$ \\
\hline \multicolumn{6}{|l|}{ Cardiovascular comorbidities, \% (n) } \\
\hline Atrial fibrillation & $2.1(19)$ & $2.0(76)$ & $3.3(46)$ & $5.3(176)$ & $8.6(107)$ \\
\hline $\begin{array}{l}\text { Chronic obstructive pulmonary } \\
\text { disease }\end{array}$ & $5.1(46)$ & $6.5(244)$ & $5.7(80)$ & $9.4(314)$ & $9.0(111)$ \\
\hline Congestive heart failure & $0.7(6)$ & $1.3(50)$ & $1.6(22)$ & $3.3(110)$ & $4.4(54)$ \\
\hline Coronary artery disease & $2.9(16)$ & $3.8(141)$ & $3.9(54)$ & $7.7(255)$ & $10.1(123)$ \\
\hline Myocardial infarction & $2.1(29)$ & $2.1(79)$ & $2.4(33)$ & $4.8(161)$ & $5.6(69)$ \\
\hline Peripheral artery disease & $1.6(14)$ & $2.6(97)$ & $3.6(50)$ & $5.7(187)$ & $9.9(120)$ \\
\hline Stroke & $0.8(7)$ & $1.7(64)$ & $2.4(34)$ & $3.5(118)$ & $3.7(46)$ \\
\hline Venous thrombo-embolism & $2.6(23)$ & $3.8(143)$ & $5.0(70)$ & 7.8 (259) & $11.0(135)$ \\
\hline
\end{tabular}

Data from the Gutenberg Health Study illustrating relative and absolute frequencies of clinical characteristics are presented. $\mathrm{IQR}$, interquartile range.

analysis excluding individuals with competing risk for oedema indicated only slightly attenuated estimates for the prevalence of venous oedema and underlined the robustness of prevalence estimates (Supplementary material online, Table S3). Prevalence estimates weighted for standard populations for the comparison to other populations are provided in the Supplementary material online, Appendix (Table S4 and S5). The frequency of self-reported symptoms associated with CVI was higher in women than in men in almost all categories of symptoms and CEAP classes. Leg pain was the most frequently reported symptom in CEAP classes $\mathrm{CO}-\mathrm{C} 2$. For $\mathrm{CVI}$, the highest prevalence of symptoms was found for leg swelling followed by leg pain (Supplementary material online, Tables S6 and S7).

\section{Cardiovascular comorbidities and Clinical-Etiologic-Anatomic- Pathophysiologic clinical conditions}

To analyse the relationship between different stages of venous insufficiency, cardiovascular risk factors, and comorbidities, regression analysis was performed. In univariate analysis, age, female sex, and all traditional cardiovascular risk factors and cardiovascular comorbidities were associated with the prevalence of CVI (Supplementary material online, Tables S8 and S9). In multivariable analysis (Supplementary material online, Figure S2), age and female sex were detected as independent predictors of all stages of the continuum of venous diseases. Chronic venous insufficiency was independently associated with an increased prevalence of arterial hypertension (PR 1.04, 95\% Cl 1.01-1.07; $P=0.004$ ), obesity (PR 1.16, 95\% Cl 1.141.19; $P<0.001)$, and active smoking (PR 1.09, 95\% Cl 1.04-1.15; $P=0.001)$ as well as cardiovascular disease (PR 1.03, 95\% Cl 1.01$1.05 ; P=0.01)$. With regard to cardiovascular disease, advanced $C V I$ (C4-C6) was specifically associated with peripheral artery disease (PR 1.13, 95\% Cl 1.04-1.24; $P=0.006$ ) and venous thrombo-embolism (PR 1.18, 95\% Cl 1.09-1.29; $P<0.001$ ). In contrast, moderate venous insufficiency (C3) did not show a significant association with specific cardiovascular disease phenotypes. Overall, a higher prevalence of cardiovascular disease was observed in advanced CVI (PR 1.10, 95\% Cl 1.03-1.17; $P=0.003$ ) than for moderate CVI (PR 1.03, 95\% Cl 1.01-1.05; $P=0.01)$ in comparison to individuals without CVI (Supplementary material online, Table S10).

Given the high burden of cardiovascular risk factors and cardiovascular disease in individuals with CVI, the role of venous disease for the prediction of cardiovascular disease was further investigated (Table 2). In multivariable regression models with adjustment for age, sex, and traditional cardiovascular risk factors, CVI was independently associated with the presence of clinically overt cardiovascular disease (PR 1.46, 95\% Cl 1.16-1.84; $P<0.001)$. This relation increased proportionally along with higher CEAP stages and was most 
pronounced for individuals with symptomatic CVI (PR 2.28, 95\% Cl $1.75-2.97 ; P<0.001)$. Coherently, the predicted risk of incident coronary heart disease according to Framingham risk score increased along with increasing severity of CVI (Figure 2A).

\section{Chronic venous insufficiency and all-cause mortality}

In order to prospectively assess the risk of all-cause death conveyed by $\mathrm{CVI}$, survival analyses were carried out. During a mean follow-up time of $6.4 \pm 1.6$ years, a total of 540 deaths were recorded. All-cause

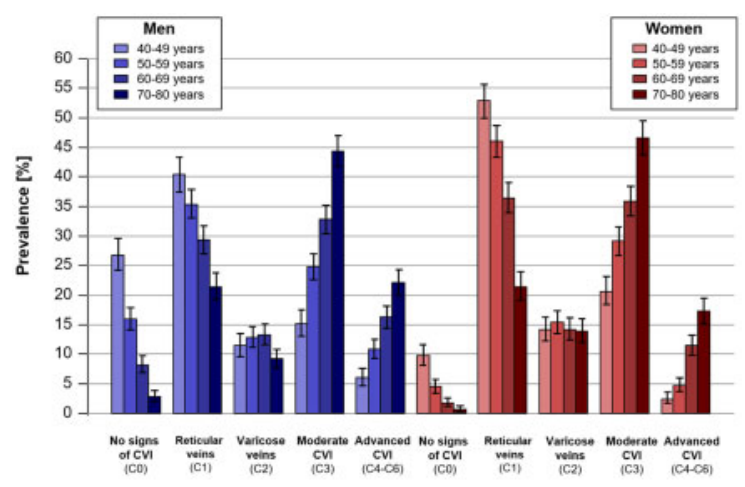

Figure I Age- and sex-specific prevalence of clinical conditions of chronic venous insufficiency in the general population. The prevalence of Clinical-Etiologic-Anatomic-Pathophysiologic clinical conditions is presented by sex and age decades in the Gutenberg Health Study. Estimates are provided with accompanying $95 \%$ confidence intervals indicated as black bars. CVI, chronic venous insufficiency. Moderate chronic venous insufficiency reflects Clinical-Etiologic-Anatomic-Pathophysiologic clinical condition C3 (chronic venous insufficiency without skin changes), whereas advanced chronic venous insufficiency reflects Clinical-Etiologic-Anatomic-Pathophysiologic clinical conditions C4-C6 (chronic venous insufficiency with skin changes). mortality was significantly higher in individuals with $\mathrm{CVI}$ (C3-C6) compared with disease-free individuals ( $P$ for difference $<0.0001$; Supplementary material online, Figure S3). Stratification of individuals with $\mathrm{CVI}$ by disease severity indicated an increase of mortality from C3 to C4-C6 (Figure 2B).

In Cox regression analysis, CVI was an age- and sex-independent predictor for all-cause death [hazard ratio (HR) 1.68, 95\% Cl 1.382.03; $P<0.0001$ ]. Pre-defined analysis with adjustment for traditional cardiovascular risk factors, cardiovascular disease, and cancer as potential risk mediators revealed CVI (HR 1.52, 95\% Cl 1.24-1.86; $P<0.0001)$ as an independent predictor of all-cause mortality (Table 3). This finding remained robust even after additional adjustment for the cardiovascular medication $(\mathrm{HR}$ 1.46, 95\% Cl 1.19-1.79; $P=0.0003$ ) and also in an analysis with cardiovascular risk factors as linear traits (data not shown).

\section{Sensitivity analysis: individuals without prevalent cardiovascular disease}

In order to exclude potential unmeasured confounding by prevalent cardiovascular disease, outcome analyses were carried out in the subsample $(n=9923)$ of individuals without prevalent cardiovascular disease (i.e. atrial fibrillation, congestive heart failure, myocardial infarction, coronary artery disease, peripheral artery disease, stroke, and venous thrombo-embolism; see Supplementary material online, Table S11 for information on clinical characteristics of the subsample).

Consistently, the presence of CVI (C3-C6) was associated with a three-fold higher risk of all-cause death compared with individuals without clinical signs of $\mathrm{CVI}(P<0.0001)$. Among individuals with $\mathrm{CVI}$, a strong and dose-dependent relationship with all-cause death was observed for moderate (C3) and advance CVI (see Supplementary material online, Figure S4). Cox regression analysis in this subsample confirmed $\mathrm{CVI}$ as an independent predictor of allcause mortality after adjustment for potential confounders and effect

Table 2 Relationship between chronic venous insufficiency and presence of cardiovascular disease

\begin{tabular}{|c|c|c|c|c|}
\hline \multirow[b]{2}{*}{ Characteristics } & \multicolumn{2}{|c|}{ Adjustment for age and sex } & \multicolumn{2}{|c|}{$\begin{array}{l}\text { Additional adjustment for traditional } \\
\text { cardiovascular risk factors }\end{array}$} \\
\hline & $\begin{array}{l}\text { Prevalence ratio } \\
(95 \% \mathrm{Cl})\end{array}$ & $P$-value & $\begin{array}{l}\text { Prevalence ratio } \\
(95 \% \mathrm{Cl})\end{array}$ & P-value \\
\hline Telangiectasia and/or reticular veins (C1) & $1.11(0.87-1.42)$ & 0.40 & $1.13(0.89-1.44)$ & 0.31 \\
\hline Varicose veins $(C 2)$ & $1.20(0.92-1.57)$ & 0.17 & $1.33(1.03-1.72)$ & 0.03 \\
\hline Chronic venous insufficiency (C3-C6) & $1.60(1.26-2.03)$ & $<0.001$ & $1.46(1.16-1.84)$ & 0.002 \\
\hline \multicolumn{5}{|l|}{ Severity of chronic venous insufficiency } \\
\hline Venous insufficiency with oedema (C3) & $1.53(1.20-1.95)$ & $<0.001$ & $1.40(1.10-1.77)$ & 0.006 \\
\hline Venous insufficiency with skin changes (C4-C6) & $1.77(1.38-2.27)$ & $<0.001$ & $1.62(1.26-2.07)$ & $<0.001$ \\
\hline Symptomatic chronic venous insufficiency $(\mathrm{C} 3-\mathrm{C} 6)$ & $2.60(1.99-3.39)$ & $<0.001$ & $2.28(1.75-2.97)$ & $<0.001$ \\
\hline
\end{tabular}




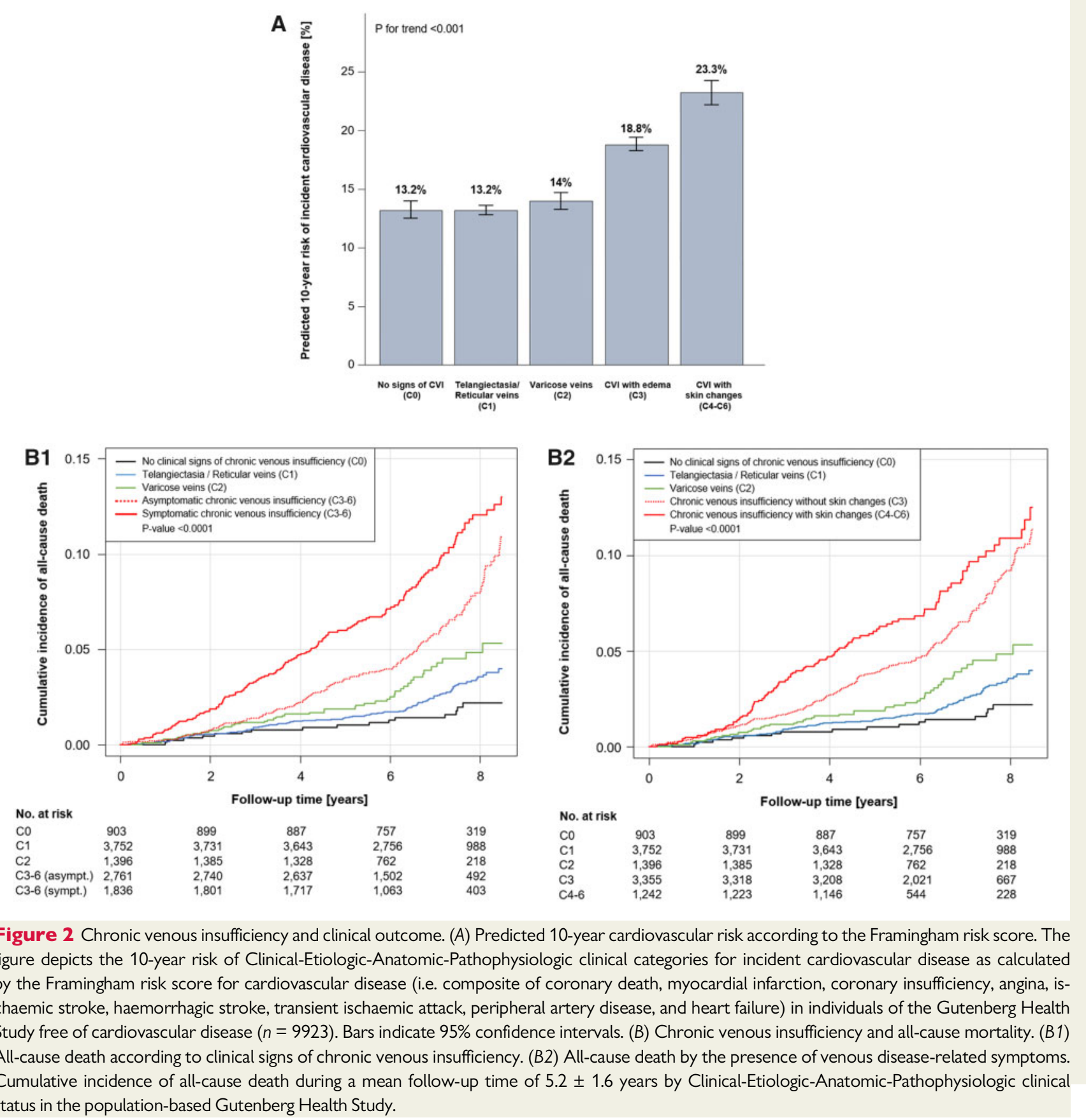

mediators (HR 1.48, 95\% Cl 1.12-1.96; $P=0.006$; see Supplementary material online, Table S12).

\section{Validation of findings in an independent prospective cohort study}

In the MyoVasc cohort, information on CEAP clinical signs of CVI was available in 2423 individuals. The mean age of the study participants was $65.6 \pm 10.5$ years and $33.3 \%(n=806)$ were women Information on the clinical characteristics of this sample is displayed in Supplementary material online, Table S13.

During a mean follow-up of $3.2 \pm 1.1$ years, deaths from any cause occurred in a total of 205 individuals in the sample. In Cox proportional hazard analysis with adjustment for age, sex, traditional cardiovascular risk factors, cardiovascular disease, cancer, $\mathrm{N}$-terminal probrain natriuretic peptide, and cardiovascular medication, 
Table 3 Multivariate Cox proportional hazards analysis of the risk of all-cause death according to clinical signs of chronic venous insufficiency

\begin{tabular}{|c|c|c|}
\hline Characteristics & $\begin{array}{l}\text { Hazard ratio } \\
(95 \% \mathrm{Cl})\end{array}$ & $P$-value \\
\hline \multicolumn{3}{|l|}{ Chronic venous insufficiency (C3-C6) } \\
\hline Adjustment for age and sex & $1.68(1.38-2.03)$ & $<0.0001$ \\
\hline Additional adjustment for cardiovascular risk factors & $1.54(1.27-1.88)$ & $<0.0001$ \\
\hline Additional adjustment for CVD and cancer & $1.52(1.24-1.86)$ & $<0.0001$ \\
\hline Additional adjustment for cardiovascular medication & $1.46(1.19-1.79)$ & 0.0003 \\
\hline \multicolumn{3}{|l|}{ Severity of chronic venous insufficiency } \\
\hline Venous disease with oedema (C3) & $1.66(1.35-2.03)$ & $<0.0001$ \\
\hline Venous disease with skin changes (C4-C6) & $1.74(1.35-2.24)$ & $<0.0001$ \\
\hline
\end{tabular}

the presence of $\mathrm{CVI}$ was found to independently predict all-cause death $(\mathrm{HR}$ 1.51, 95\% Cl 1.11-2.05; $P=0.009)$ (see Figure 3 and Supplementary material online, Table S14).

\section{Discussion}

The present study represents the largest population-based investigation of the full spectrum of CVI to date. The major findings of this study are that (i) CVI has a high prevalence in the population, (ii) cardiovascular disease and $\mathrm{CVI}$ are interdependent and share risk factors, and (iii) $\mathrm{CVI}$ represents a strong predictor for all-cause mortality in the general population beyond established risk factors (Graphical abstract). The association with all-cause death was externally replicated in an independent cohort.

The results of the present study provide the latest populationbased, sex-specific prevalence estimates in a developed country of predominantly white ancestry. The current study underlines the high burden of chronic venous disorders in the population assessed by CEAP clinical categories: the prevalence of varicose veins (C2) was $13.3 \%$ and of clinically overt CVI (C3-C6) $40.8 \%$ making venous disease by far the most prevalent vascular disease in the population. In line with previous reports, only $9.4 \%$ of the population (age range: $40-80$ years) showed no clinical signs of venous disease in the present study. ${ }^{14}$ In the literature, estimates for the prevalence of venous insufficiency vary widely and range from $<1 \%$ to $73 \%$ by study setting, methodology, and study population. ${ }^{5,15,16}$ In contrast to the more frequent presentations of $\mathrm{CVI}$, i.e. oedema (C3) or skin changes without ulceration (C4), the prevalence of venous ulcers (C5/C6) was very low in the present study and confirms reports of smaller sample size. ${ }^{17}$ To avoid bias, a highly standardized data assessment with rigorous data control was applied and sensitivity analysis performed to exclude misclassification. These results are of particular interest when considering that the magnitude and impact of venous insufficiency are prone to an under-appreciation.
Although the present study does not establish a causative role of CVI for the development of atherosclerosis and arterial cardiovascular disease, it suggests the existence of a link between arterial and venous vascular disease, which might be partly explained by shared risk factors. Very recently, a retrospective Taiwanese study using claims data reported that the presence of varicose veins was associated with an increased incidence of venous thrombo-embolism and peripheral artery disease. ${ }^{6}$ These observations are complemented by data from the Framingham Heart Study demonstrating that individuals with varicose veins experience a higher incidence of future atherosclerotic cardiovascular disease than those without varicose veins, especially for coronary heart disease. ${ }^{18}$ Since CVI was related with cardiovascular disease independent of traditional cardiovascular risk factors and comorbidities in the present study, the findings suggest a potential cross-talk between arterial and venous vascular beds. This adds to already existing integrative approaches to vascular disease by highlighting the importance of 'venous disease' as vascular disease in terms of cardiovascular disease, which is till now most commonly thought to be related to arterial vascular disease only. ${ }^{19}$ Since systemic inflammation is commonly accepted to play a pivotal role in the development and progression of both arterial and venous vascular disease, ${ }^{2,20}$ it is conceivable that structural and functional inflammation-mediated alterations in the endothelium in both vascular beds might be the consequence of the exposure to traditional cardiovascular risk factors. This may also lead to a systemic cross-talk via overarching shared mechanisms such as autonomic imbalance. ${ }^{19,21}$

In the present study, age and female sex were confirmed as risk factors of CVI, which have been reported earlier by others, ${ }^{5}$ but interestingly also for earlier disease stages. The current pathophysiological understanding is that venous vessels experience vascular ageing due to venous hypertension, which subsequently leads to gradual deterioration of the vessel wall and valve competence over time. ${ }^{5}$ With regard to female sex, studies indicate that physiological changes during pregnancy (e.g. increase in blood volume and body composition) and direct effects of sex-steroid hormones are relevant for the 


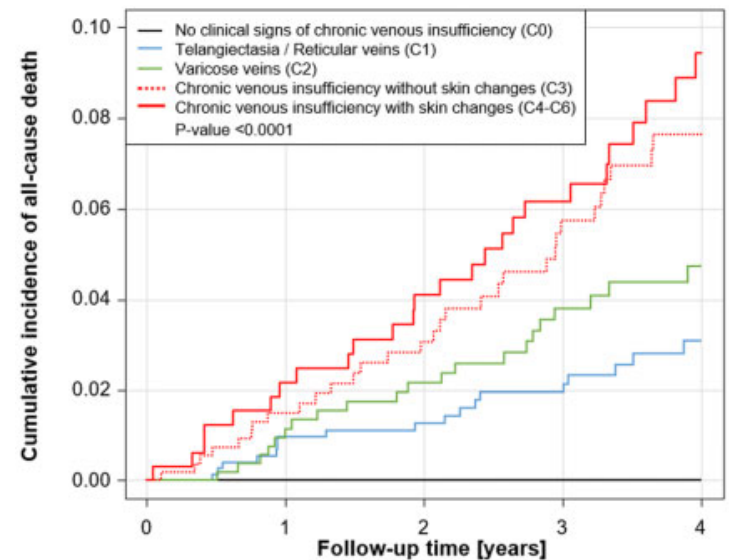

No. at risk

$\begin{array}{llllll}\text { C0 } & 206 & 195 & 173 & 147 & 108 \\ \text { C1 } & 751 & 684 & 637 & 535 & 331 \\ \text { C2 } & 536 & 501 & 466 & 393 & 250 \\ \text { C3 } & 543 & 478 & 411 & 334 & 256 \\ \text { C4-6 } & 326 & 312 & 289 & 262 & 164\end{array}$

Figure 3 Validation of the independent relationship of chronic venous insufficiency with all-cause death in a cohort study. Cumulative incidence of all-cause death during a mean follow-up time of $3.2 \pm 1.1$ years by clinical signs of chronic venous insufficiency in the MyoVasc Study. The adjusted hazard ratio is displayed from Cox proportional hazard model with adjustment for age, sex, traditional cardiovascular risk factors (i.e. arterial hypertension, diabetes mellitus, dyslipidaemia, positive family history of myocardial infarction and/or stroke, obesity, and smoking), cardiovascular disease (i.e. composite of coronary death, myocardial infarction, coronary insufficiency, angina, ischaemic stroke, haemorrhagic stroke, transient ischaemic attack, and peripheral artery disease), cancer, and cardiovascular medication [i.e. antithrombotic agents (ATC code B01), cardiac therapy (C01), antihypertensive drugs (C02), diuretics (C03), beta-blockers (C07), calcium channel blockers (C08), agents interacting with the renin-angiotensin system (i.e. angiotensin-converting enzyme inhibitors and angiotensin I receptor blockers; C09), and lipid-modifying agents (C10)].

pathophysiology. ${ }^{22}$ Hypercoagulability associated with pregnancy ${ }^{23}$ and the use of oral contraceptives ${ }^{24}$ provide further explanations for the increased risk of CVI in women. Considering the high prevalence of venous insufficiency in the population, it is noteworthy that cardiovascular risk factors and comorbidities were highly prevalent in individuals with CVI. The results substantiated the notion that cardiovascular comorbidities show a distinct profile throughout the continuum of venous insufficiency. ${ }^{25}$ Age, female sex, diabetes mellitus, obesity, arterial hypertension, smoking, and cardiovascular disease were detected as independent predictors of CVI, whereas only age and female sex were associated with a higher risk for the presence of varicose veins, telangiectasia, or reticular veins. This adds to the limited literature available by suggesting that smoking and in particular obesity, which is known to contribute to venous stasis and systemic inflammation, are in fact risk factors for the development of $\mathrm{CVI}^{26}$ This is of specific importance given the high public health impact of both conditions. ${ }^{27}$ For arterial hypertension and cardiovascular disease, only a few studies have so far reported an independent relation to $\mathrm{CVI}{ }^{7}$ Against the limited body of evidence available, the present study supports an interdependence of venous and arterial hypertension. Peripheral vascular remodelling and systemic inflammation with subsequent hypercoagulability represent commonalities, which may explain the relevance of hypertension for the disease pathology in both vascular beds. ${ }^{28}$

\section{Strengths and limitations}

The major strengths of the present study represent the populationbased setting and comprehensive phenotyping of individuals by specially trained staff in a dedicated study centre. All data including clinical outcomes were recorded in a highly reproducible and standardized manner. Nevertheless, some limitations merit consideration: CEAP grading of venous insufficiency was limited to the clinical status as documented by standardized photographic documentation and subsequently analysed by trained staff. Although a large panel of covariates was considered in regression analyses, unmeasured confounding (e.g. introduced by limited physical activity or nutrition) cannot be ruled out completely. However, verification of the relationship between CVI and all-cause death in the subsample of individuals free of prevalent cardiovascular disease as well as the external replication of study findings in an independent cohort support the validity and robustness of the data. Further investigations in other settings will help to explore the generalizability of results (e.g. by analysis of different population cohorts and specific diseased cohorts). Future research should evaluate the pathophysiology linking the relationship of CVI with arterial cardiovascular disease.

\section{Conclusions}

The present study demonstrates that $\mathrm{CVI}$ is related to cardiovascular disease and is predictive of all-cause death. The data call for an increased awareness of the prevalence and clinical implications of the disease beyond cosmetic issues. This work opens up important new tasks for future research, including experimental studies, investigations related to subclinical disease pathology, and possibly interventions. Environmental factors (e.g. occupation), diet, imaging modalities, and genetic variance ${ }^{29}$ will play a role in this context. Assessment of the clinical signs of CVI may also represent an interesting approach to improve risk stratification through early detection of cardiovascular disease and associated risk factors in individuals with this condition.

\section{Supplementary material}

Supplementary material is available at European Heart Journal online.

\section{Acknowledgements}

The authors are indebted to the study participants of the Gutenberg Health Study and the MyoVasc Study and the study staff for their contribution and commitment. Part of this work is part of the doctoral theses of Andrea Falcke (GHS cohort) and Sophie Moll (MyoVasc cohort). The graphical abstract, which was created by BioRender, contains a graphical illustration licensed by Adobe Stock (\#300118836). 


\section{Funding}

This work was supported by the Federal Ministry of Education and Research (BMBF 01EO1503). The Gutenberg Health Study (GHS) was supported by the government of Rhineland-Palatinate ('Stiftung Rheinland Pfalz für Innovation', contract no. AZ 961-386261/733), the research programmes 'Wissen schafft Zukunft' and the Center for Translational Vascular Biology (CTVB) of the Johannes Gutenberg-University Mainz, and its contract with Boehringer Ingelheim and Philips Medical Systems including an unrestricted grant for the Gutenberg Health Study. The MyoVasc study was funded by the German Center for Cardiovascular Research (DZHK).

Conflict of interest: J.H.P., M.P.-N., and P.S.W. are funded by the Federal Ministry of Education and Research (BMBF 01EO1503). P.S.W. reports grants and personal fees from Boehringer Ingelheim, sanofiaventis, and Bayer Vital; grants from Philips Medical Systems, Daiichi Sankyo Europe, and Evonik; personal fees from Bayer HealthCare and Astra Zeneca; personal fees and non-financial support from DiaSorin; and non-financial support from I.E.M. J.H.P. reports fees for lecturing from Bayer AG and Boehringer Ingelheim $\mathrm{GmbH}$ not related to the present work. P.S.W. and T.M. are principal investigators of the German Center for Cardiovascular Research (DZHK). P.S.W. is the principal investigator of the DIASyM research core (BMBF 161L0217A).

\section{References}

1. Raju S, Neglen P. Clinical practice. Chronic venous insufficiency and varicose veins. N EnglJ Med 2009;360:2319-2327.

2. Bergan JJ, Schmid-Schonbein GW, Smith PD, Nicolaides AN, Boisseau MR, Eklof B. Chronic venous disease. N Engl J Med 2006;355:488-498.

3. Hamdan A. Management of varicose veins and venous insufficiency. JAMA 2012; 308:2612-2621.

4. Eberhardt RT, Raffetto JD. Chronic venous insufficiency. Circulation 2014;130: 333-346.

5. Beebe-Dimmer JL, Pfeifer JR, Engle JS, Schottenfeld D. The epidemiology of chronic venous insufficiency and varicose veins. Ann Epidemiol 2005;15:175-184.

6. Chang SL, Huang YL, Lee MC, Hu S, Hsiao YC, Chang SW, Chang CJ, Chen PC. Association of varicose veins with incident venous thromboembolism and peripheral artery disease. JAMA 2018;319:807-817.

7. Prandoni P. Links between arterial and venous disease. J Intern Med 2007;262: 341-350.

8. Piazza G. Varicose veins. Circulation 2014;130:582-587.

9. Wild PS, Zeller T, Beutel M, Blettner M, Dugi KA, Lackner KJ, Pfeiffer N, Munzel T, Blankenberg S. [The Gutenberg Health Study]. Bundesgesundheitsblatt Gesundheitsforschung Gesundheitsschutz 2012;55:824-829.

10. Brodovicz KG, McNaughton K, Uemura N, Meininger G, Girman CJ, Yale SH. Reliability and feasibility of methods to quantitatively assess peripheral edema. Clin Med Res 2009;7:21-31.
11. Rutherford RB, Padberg FT Jr, Comerota AJ, Kistner RL, Meissner MH, Moneta GL. Venous severity scoring: an adjunct to venous outcome assessment. J Vasc Surg 2000;31:1307-1312.

12. Göbel S, Prochaska JH, Tröbs SO, Panova-Noeva M, Espinola-Klein C, Michal M, Lackner KJ, Gori T, Münzel T, Wild PS. Rationale, design and baseline characteristics of the MyoVasc study: a prospective cohort study investigating development and progression of heart failure. Eur J Prev Cardiol 2020; doi: 10.1177/2047487320926438.

13. D’Agostino RB, Vasan RS, Pencina MJ, Wolf PA, Cobain M, Massaro JM, Kannel WB. General cardiovascular risk profile for use in primary care: the Framingham Heart Study. Circulation 2008;117:743-753.

14. Rabe E, Guex JJ, Puskas A, Scuderi A, Quesada F. Epidemiology of chronic venous disorders in geographically diverse populations: results from the Vein Consult Program. Int Angiol 2012;31:105-115.

15. Criqui $M H$, Jamosmos M, Fronek A, Denenberg JO, Langer RD, Bergan J, Golomb BA. Chronic venous disease in an ethnically diverse population: the San Diego Population Study. Am J Epidemiol 2003;158:448-456.

16. Evans CJ, Fowkes FG, Ruckley CV, Lee AJ. Prevalence of varicose veins and chronic venous insufficiency in men and women in the general population: Edinburgh Vein Study. J Epidemiol Community Health 1999;53:149-153.

17. Bradbury A, Evans C, Allan P, Lee A, Ruckley CV, Fowkes FG. What are the symptoms of varicose veins? Edinburgh vein study cross sectional population survey. BMJ 1999;318:353-356.

18. Brand FN, Dannenberg AL, Abbott RD, Kannel WB. The epidemiology of varicose veins: the Framingham Study. Am J Prev Med 1988;4:96-101.

19. Abboud FM. The Walter B. Cannon Memorial Award Lecture, 2009. Physiology in perspective: the wisdom of the body. In search of autonomic balance: the good, the bad, and the ugly. Am J Physiol Regul Integr Comp Physiol 2010;298: R1449-R1467.

20. Ross R. Atherosclerosis—an inflammatory disease. N Engl J Med 1999;340:115-126.

21. Tsuji H, Larson MG, Venditti FJ Jr, Manders ES, Evans JC, Feldman CL, Levy D. Impact of reduced heart rate variability on risk for cardiac events. The Framingham Heart Study. Circulation 1996;94:2850-2855.

22. Stansby G. Women, pregnancy, and varicose veins. Lancet 2000;355:1117-1118.

23. Greer IA. Thrombosis in pregnancy: maternal and fetal issues. Lancet 1999;353 1258-1265.

24. Vandenbroucke JP, Rosing J, Bloemenkamp KW, Middeldorp S, Helmerhorst FM, Bouma BN, Rosendaal FR. Oral contraceptives and the risk of venous thrombosis. N Engl J Med 2001;344:1527-1535.

25. Prandoni P, Bilora F, Marchiori A, Bernardi E, Petrobelli F, Lensing AW, Prins $\mathrm{MH}$, Girolami A. An association between atherosclerosis and venous thrombosis. N Engl J Med 2003;348:1435-1441.

26. Gourgou S, Dedieu F, Sancho-Garnier H. Lower limb venous insufficiency and tobacco smoking: a case-control study. Am J Epidemiol 2002;155:1007-1015.

27. Allison MA, Cushman M, Callas PW, Denenberg JO, Jensky NE, Criqui MH Adipokines are associated with lower extremity venous disease: the San Diego population study. J Thromb Haemost 2010;8:1912-1918.

28. Cushman M, Callas PW, Allison MA, Criqui MH. Inflammation and peripheral venous disease. The San Diego Population Study. Thromb Haemost 2014;112:566-572.

29. Fukaya E, Flores AM, Lindholm D, Gustafsson S, Zanetti D, Ingelsson E, Leeper NJ. Clinical and genetic determinants of varicose veins. Circulation 2018;138. 2869-2880. 